\title{
Enhancing Pupils' Understanding of the Human Skeleton Using a Designed Human Skeletal Model
}

\author{
F. Awuah ${ }^{1,2^{*}}$, A. Dominic ${ }^{2}$ \\ ${ }^{1}$ Department of Theoretical and Applied Biology, Kwame Nkrumah University of Science and Technology, Kumasi, Ghana \\ ${ }^{2}$ Department of Science, Abetifi Presbyterian College of Education, Abetifi Kwahu, Ghana \\ Email: pasawuah@gmail.com
}

Received: 5 August 2020; Revised: 4 February 2021; Accepted: 21 February 2021

\begin{abstract}
The research was necessitated due to the researcher's experience of the difficulty of pupils of Pepease Presbyterian Basic Six in the understanding of the human skeleton. The total number of thirty-three pupils in this class, Pepease Presbyterian Basic Six was the population of this study which employed an action research method. The study revealed that pupils performed better in a lesson on the human skeleton aided by the skeletal model designed by the researcher than when presented theoretically. The research instruments employed in this study were interview, test and questionnaire. The model of the human skeleton, designed teaching and learning material used served its purpose so well and this reflected in pupils' performance which had improved remarkably after the intervention. The present study, therefore, recommends intermittent in-service training for Science Teachers especially those in the remote areas on how to design improvised materials for the various topics in the Basic Schools Science Syllabus.
\end{abstract}

Keywords: teaching learning material (TLM), basic school, pupils, skeletal model, human skeleton, science teachers

\section{Introduction}

Science forms the basis for inventions, manufacturing and simple logical thinking geared towards making the environment a better place to live. Levy (2007) observed that basic education forms the basis of human resource development. Therefore, the adoption of teaching learing materials (TLMs) in teaching will form the fundamental basis for growth and development of the potentials, competencies, abilities, capabilities, aptitudes and values of learners. However, (Chakaninka et al., 2012; Mtsi \& Maphosa, 2016) are of the assertion that most rural Basic Schools in Africa are marked by a shortage of TLMs.

According to Kapur (2019) and Bušljeta (2013), the TLMs should be given greater attention as a major aspect that would promote students learning and help in the realization of academic goals and objectives. For this reason, teachers and other stakeholders in education need to focus on bringing about developments in the TLMs.

According to Adu-Gyamfi (2013), students' repulsive attitude to science is due to the fact that the subject has been allowed to be taught in less practical nature. That is to say, teaching and learning of science has become the transfer of knowledge from science teachers and textbooks to students. Furthermore, Adu-Gyamfi (2014) in deducing the challenges faced by the integrated science teachers stated that their major one among the challenges is the unavailability of Teaching and Learning Materials.

Copyright (C2021 F. Awuah, et al.

DOI: https://doi.org/10.37256/ser.222021565

This is an open-access article distributed under a CC BY license

(Creative Commons Attribution 4.0 International License)

https://creativecommons.org/licenses/by/4.0/ 
Most Educators believe that instructional resources enhance lesson delivery and learning process, enable teachers and students to interact and control their learning environment for better results (Olawale, 2013; Igbo \& Omeje, 2014). It is interesting to note that the use of instructional resources breaks the language barriers, saves time, helps teachers to use different teaching and learning methods and enables students to have a better conceptual understanding of the search image.

According to Effiong, \& Igiri (2015), instructional materials are tools locally made or imported that help to facilitate the teaching/learning process. It is rather unfortunate that most teachers at the basic level neglect the fact that without the provision of TLMs by the government for them to teach, they could also gather the local materials and with the assistance of the pupils prepare their own.

In an attempt to relate TLMs to the teacher and learner (Olayinka, 2016; Adalikwu \& Iorkpilgh, 2013) state that instructional materials serve as the channel between the teacher and the students in delivering instructions and the motivation on the teaching-learning process. They are used to capture students' attention and get rid of boredom.

The main purpose of science teaching is to provide the workforce in the science and technology and also inspire students with a desire to self-improvement and achievement of excellence (Kraiger \& Ford, 2020; Brown et al., 2013). However, without TLMs in science teaching, rote learning is encouraged and pupils are therefore trained in this case to "chew, pour and forget" (learning only for examination).

Ibrahim (2012) claims that adequate instructional materials in science teaching should be provided in order to meet the standards of science teaching. According to Adalikwu and Iorkpilgh (2013), instructional materials possess some inherent advantages that make them unique in teaching. They provide the teacher with interesting and compelling platforms for conveying information since they motivate for more learning. Most students are Science phobias because the way the subjected is presented to them as something that is heard but not really in existence or as a mystery (Driessen et al., 2020).

Adeyemo (2010) indicated that one cannot dissociate the poor performance of students in a lesson to its abstractness. Unfortunately, the Science teachers in the area under study result in abstract ways to handle their lessons and hence the low achievement of the pupils observed by the researchers.

Adeymo (2010) and Moreno-Guerrero et al. (2020) observed that teachers have it as responsibility to put into action their creativity and innovativeness in selecting and using instructional materials among others to motivate students to learn in the context of their learning environment.

The government of Ghana in the quest to improve upon the quality of science and technology in Ghana stresses on Science Education in the Vision 2020 and therefore one of the basic objectives of Vision 2020 is to develop adequate scientific and technological capabilities to lead to infrastructural development which will enable industries and other sectors of the economy to provide the basic needs of the nationals (Towsep \& Anamuah-Mensah, 1991). To realize this vision, basic Education in Science should be made concrete to boost the interest of the future generation in Science. This cannot be done without the use of TLMs in teaching science, especially at the basic Schools. In the observation made by Shri (2013), TLMs are aids used by the teacher to teach effectively to enable learners to learn effectively.

Again, Yeboah et al. (2019) stated that developing countries, including Ghana, are not able to provide teachers with instructional resources for teaching and learning due to financial constraints, hence science, in particular, is a subject that pupils and students in Ghana generally do not perform well both at the basic and senior high levels which are evident from the end of level examinations over the years. Ghana as a developing country for that matter is trailing behind other countries in her development due to the low level of scientific advancement because Science as a discipline seems to be not attractive to a lot of students due to the abstract nature in which the subject is taught at the basic level, a problem teachers attribute to the governments' inability to provide schools with science TLMs.

Benson and Odera (2013), simplifies the need for TLMs in the delivery of lessons more especially that of Science by stating that, the primary purpose of instructional materials is to make teaching and learning more effective and also facilitate it.

Pepease Presbyterian Basic School where this research was undertaken is situated in the heart of Pepease, a relatively small community in the Kwahu-East District of the Eastern Region of Ghana is of no exception.

Little is known about the use of TLMs in handling topics such as "The Human Skeleton" in the study area.

The study, therefore, seeks to improve pupils' understanding of the Human Skeleton through the researcher's own designed skeletal model in addressing the challenge in obtaining TLMs to teach the topic, "The Human Skeleton". 


\subsection{Statement of the problem}

It is observed that Pepease Presbyterian Basic School lacks the basic TLMs for the teaching of most topics in science, especially that of the human skeleton. Therefore, Pupils find it difficult to grasp the concept behind the human skeleton and hence perform poorly when a lesson on the human skeleton is evaluated.

\subsection{Purpose of the study}

The purpose of this study was to investigate the effects of integrating the researcher's own designed skeletal model to aid teaching and learning of the "Human Skeleton" at the Pepease Presbyterian Basic Six.

\subsection{Research question}

To what extent the integration of the researcher's designed skeletal model into teaching and learning helps to improve pupils' performance in the "Human Skeleton"?

\subsection{Significance of the study}

1. The study will help Science teachers in the Pepease Presbyterian Basic School to deliver lessons on the human skeleton at ease.

2. This research will help Ministry of Education and Ghana Education Service to organize in-service training for Basic School Teachers to abreast them with how to organize local materials to prepare TLMs, especially the remote area where TLMs are mostly lacking.

In addition, the data collected will also help future researches into improvisation.

\subsection{Hypothesis (Ho 1)}

There is no significant difference between the performance of students in the lesson on "The Human Skeleton" taught using the researcher's own designed skeletal model and that taught in abstract.

\section{Methodology}

The methodology unfolds the research design chosen for the study, research instruments, the population, sample size and the sampling procedure adopted for successful research.

It also includes among other things, a thorough and explicit description of a set of planned and implemented strategies bordering on the problem in question for which the study was undertaken.

\subsection{Research design}

The action research design was the choice of the researcher amongst the options offered since it is research directed towards finding ways of solving a noticed problem in the most practical way possible in an immediate environment.

Otherwise stated, it is the on-the-spot procedure designed to deal with concrete problems located in an immediate situation and this completely suits the researcher as the main intention is to find a remedy to a group of distinct pupils who have problems concerning the study of the human skeleton.

It is also worth noting that the action research, as it is activity-based, makes the outcome of the research more real and vivid after the implementation of well planned and structured procedures, thereby erasing the abstraction connected to the study. This enables the researcher to decide whether the strategies adopted call for further modifications whilst the target group involved benefits also by grasping and comprehending easily, and suggested solutions to the problem studied.

However well, the action research may suit the problem under study; it leaves quite a noticeable dent in one's 
finances as well as the considerable amount of time it requires which cannot be overemphasized.

\subsection{Population and sample selection}

The population selected for this study was the Pepease Presbyterian Basic School class Six pupils, of which Sixteen (16) were females and Seventeen (17) were males, totalling Thirty-three (33).

\subsection{Sample size}

Twenty (20) pupils constituting a subset of the total population of Thirty-three (33) pupils were selected for the study. This number of pupils was selected as the sample size because it gives a fair representation of the population.

\subsection{Sampling procedure}

Purposive sampling was the technique adopted in the selection of the subjects associated with the study of the various procedures available. The researcher realized that the afore-mentioned procedure was more ideal and convenient since it reflected the purpose of the investigation which was to enhance the performance of pupils who failed to provide appropriate and expected solutions to an exercise during an evaluation lesson on the human skeleton.

\subsection{Research instruments}

In addressing the problem of pupils' inability to grasp the concept of the human skeleton, the researcher adopted certain techniques including the use of tools of enquiry like the questionnaire, interview and test to acquire substantive data on the problem.

\subsubsection{Questionnaire}

The researcher administered the questionnaire, an inquiry document containing systematically a compiled and well-organized series of questions direct in nature intended to be used in eliciting information based on pupils' inability to perform well in the topic consequently providing more insight into the nature of the problem under study and this was administered to the respondents who were teachers and pupils. The questionnaire consisted of five sections: A, B, C, D, and E. Section A elicited information about the demography of the respondents. With regard to section B, the items were to seek information about pupils' perception about science. While the section C sought information about the teachers' difficulty in handling "The human Skeleton" as a topic in the science syllabus. Information about the strategies adopted by the teachers in handling the topic was obtained in the section D. Last but not least, section E was to find information about the resources and materials for teaching and learning of the human skeleton.

\subsubsection{Interview}

The permanent class teacher and pupils alike were interviewed by the researcher, a two-way and one-on-one approach in which there was an exchange of ideas, information and suggested possible ways from the interviewees on how the subjects could be delivered by teachers who will undoubtedly lead to an improvement in pupils' performance on the existing problem.

\subsubsection{Test}

Tests were conducted at both the pre-intervention and the post-intervention stages. The details of these are described in the intervention process.

\subsection{Intervention process}

The intervention process consisted of pre-intervention, intervention and post-intervention. In the pre-intervention stage, the intensity of the problem was identified. The pupils did not participate actively in class. They would not 
attempt to ask questions in class. A pre-test was administered to determine the achievement of the Pupils after a lesson on the human skeleton. In the intervention stage, the researcher's skeletal model was introduced to teach a 30-minute lesson of the same class. Here the teacher taught the lesson at ease with a high level of participation on the part of the students. The researcher then went ahead with the post-intervention in which the extent to which the intervention has impacted on pupils' performance was found out through a post-test and the data recorded used to answer the research questions.

\subsection{Validity and reliability}

In the establishment of the Validity and the reliability of the instrument, the supervisors of this research were asked to evaluate and approve the items and make sure that the various sections of research instruments and their various items are in agreement with the objective of the study. The comments made and the suggestions given were taken into consideration in the modification of the original instrument. The interview questions and the test items were constructed and moderated by the selected well-qualified senior lecturers of Abetifi Presbyterian College of Education. The tests were administered under very strict supervision. The inter-rater reliability was employed to determine consistency in the rating of the pupils.

The respondents were contacted, and questionnaires were administered to them. After the items were answered, few key questions were selected and asked again and the responses compared with the ones provided earlier by the same respondents (Rodrigues et al., 2019).

\section{Results and discussion}

\subsection{Introduction}

This chapter seeks to present and discuss both the pre-test and the post-test results. The results indicate that students performed better in the post-test than in the pre-test.

\subsection{Pre-test results}

Table 1 presents the frequency distribution of pre-test results. In other words, the table illustrates the results obtained from students before the intervention was introduced to teach the concept of the human skeleton. The performance of the students as seen in the table was not encouraging.

Table 1. Frequency distribution of pre-test results

\begin{tabular}{ccccccc}
\hline & \multicolumn{5}{c}{ Pre-intervention Results } & Total $(\Sigma)$ \\
\hline Scores (x) & 4 & 3 & 2 & 1 & 0 & 20 \\
Frequency (f) & 3 & 4 & 2 & 5 & 6 & 33 \\
fx & 12 & 12 & 4 & 5 & 0 & 33 \\
\hline
\end{tabular}

It can be seen in Table 1 that, the entire students in the class scored less than five. That is, none of the students could obtain half of the total marks of ten.

\subsection{Post-test results}

Frequency distribution of post-test results is illustrated in table 2. In this table, the performance of the students after the intervention (the researcher's designed skeletal model was introduced to teach the lesson on the human skeleton) is clearly shown. The achievement of the students at this stage seems encouraging. 
Table 2. Frequency distribution of post-test results

\begin{tabular}{ccccccc}
\hline & & Post-intervention Results & Total $(\Sigma)$ \\
\hline Scores (x) & 10 & 9 & 8 & 7 & 6 & \\
Frequency (f) & 6 & 5 & 4 & 2 & 3 & 20 \\
$\mathrm{fx}$ & 60 & 45 & 32 & 14 & 18 & 169 \\
\hline
\end{tabular}

Table 2 reveals that no student scored less than six out of the total marks of ten in the post-test. It is also seen that 15 out of the 20 students scored not less than eight when the intervention was introduced.

\subsection{Difference between pre-test and post-test}

Table 3 shows the difference between the pre-test and post-test results. To find out whether there was a significant difference between the performance of the students in the pre-test and the post-test, a T-test was conducted at 0.05 significant level. Table 3 presents the results of this T-test.

Table 3. Determination of significant difference between the pre-test and the post-test results

\begin{tabular}{ccccc}
\hline Test p-value & Mean & variance & t-value & df \\
\hline Pre-test & 1.65 & 2.239 & 2.024 & 38 \\
Post-test & 8.45 & & & \\
\hline
\end{tabular}

Table 3 illustrates that the mean score of the class under consideration in the pre-test is 1.65 with that of the post-test when the intervention was introduced being 8.45 which is a higher score than the one recorded when the intervention was not introduced. Table 3 indicates that there is a statistically significant difference between the pre-test and the post-test results $(\mathrm{P}<0.05)$. The null hypothesis is therefore not accepted.

\subsection{Students'performances}

Critical observation of Table1, Table 2 and Table 3, reveals that the difference in the pre-test and post-test results is due to the incorporation of the intervention, namely the researcher's own designed skeletal model in the lesson of the human. This can be explained that in both the pre-intervention and the intervention stages, all other conditions were kept constant except for the introduction of the skeletal model that was introduced in the intervention stage.

Since the skeletal model used was made from the locally available materials in the environment of the pupils, it made them appreciate the use of everyday materials in their environment in the learning of Science. This is to say that the intervention removed the misconception on the part of the pupils which makes them consider science as a mystery and hence the lesson, in this case, was demystified. Although the original material was not available, the resourcefulness on the part of the researcher to improvise from the readily available material in the environment appealed the lesson to the senses of the pupils. They could therefore interact with the TLM. This is in agreement with (Frimpong et al., 2019; Okobia, 2011), which attest that the use of the indigenous resources as TLMs in Science lessons assists to reduce the level of abstraction and bring concreteness in teaching and learning process and help students to visualize, conceptualize and understand the selected concept, thereby making lessons real and meaningful. The designed instructional material is, therefore, the secret behind the higher achievements of the students in the post-test than in the pre-test. Students taught with instructional resources in science perform creditably well compared with their counterparts taught without instructional materials (Nwike \& Catherine, 2013; Effiong \& Igiri, 2015; Opare et al., 2018). 


\subsection{Conclusion and recommendation}

The researcher's own designed skeletal model in this study could solve the problem of lack of TLMs in the teaching of the lesson on the human skeleton. This is to say that pupils in Pepease Presbyterian Basic Six performed far better when the said designed skeletal model was used in the lesson delivery than when the lesson was taught in abstract. There was a statistically significant difference $(\mathrm{p}<0.05)$ between the pre-test and post-test results of the population in this study.

It can therefore be concluded that in the school communities especially very remote areas where there is lack of Science TLMs, the solution is to good abreast Science Teachers on the need to improvise and how to prepare these Teachers to improvise TLMs for their lessons.

It is therefore recommended that Ghana Education Service and other stakeholders of Basic Education in Ghana need to organize intermittent in-service training for Science Teachers especially those in the remote areas of the country on how to design improvised materials for the various topics in the Basic Schools Science Syllabus.

Science teachers in areas where materials to teach are difficult to come by should develop the "can-do spirit" that despite the governments in the inability to provide TLMs for their lessons, they could provide their ones to teach the various topics in the syllabus.

\section{Acknowledgements}

Blessed is the Lord God Almighty for the great things He has done, the energy and the persistence given to us to complete this work. Dr Samuel Appah also deserves our thanks for his support and encouragement during this process. Last but not least, Mrs Joyce Awuah and the whole of Awuah's family deserve greater gratitude for their invaluable patience and the encouragement during the preparation of this work.

\section{References}

Adalikwu, S. A., \& Iorkpilgh, I. T. (2013). The influence of instructional materials on academic performance of Senior Secondary School students in Chemistry in Cross River State. Global Journal of Educational Research, 12(1), 3946.

Adeyemo, S. (2010). Teaching/learning physics in Nigerian secondary school: The curriculum transformation, issues, problems and prospects. International Journal of Educational Research and Technology, 1(1), 99-111.

Adu-Gyamfi, K. (2013). Lack of interest in school science among non-science students at the senior high school level. Problems of Education in the 21st Century, 53(53), 7-21.

Adu-Gyamfi, K. (2014). Challenges face by science teachers in the teaching of integrated science in Ghanaian Junior High schools. Journal of Science and Mathematics Education, 6(2), 59-80.

Benson, A., \& Odera, F. (2013). Selection and use of media in teaching Kiswahili language in secondary schools in Kenya. International Journal of Information and Communication Technology Research, 3(1), 2223-4985.

Brown, L., Eshiet, L. T., \& Nkem, B. A. (2013). The Use of instructional materials in the teaching of science as fundamental of education technology. Lagos: Johns Lod Publisher Ltd, Lagos.

Bušljeta, R. (2013). Effective use of teaching and learning resources. Czech-polish Historical and Pedagogical Journal, $5(2), 55$.

Chakaninka, W. W., Sichula, N. K., Sumbwa, P. I., \& Nduna, M. (2012), The challenges of rural education in Africa. South Africa Rural Educator. https://www.researchgate.net/publication/336676604

Driessen, E. P., Knight, J. K., Smith, M. K., \& Ballen, C. J. (2020). Demystifying the meaning of active learning in postsecondary biology education. CBE-Life Sciences Education, 19(4), ar52.

Effiong, O. E., \& Igiri, C. E. (2015). Impact of instructional materials in teaching and learning of biology in senior secondary schools in Yakurr LG A. International Letters of Social and Humanistic Sciences, 62, 27-33.

Ibrahim A. I. (2014). Restructuring science teaching in nigerian tertiary institutions. American Journal of Educational Research, 2(11), 1100-1103.

Igbo, J. N., \& Omeje, J. C. (2014). Perceived efficacy of teacher-made instructional materials in promoting learning among mathematics-disabled children. Sage Open, 4(2), 1-6. 
Kapur R. (2019, June). Development of teaching-learning materials. https://www.researchgate.net/publication/ 334083571

Kraiger, K., \& Ford, J. K. (2020). The science of workplace instruction: Learning and development applied to work. Annual Review of Organizational Psychology and Organizational Behavior, 8(1), 45-72.

Levy, S. (2007). An inquiry into motivation using the case of phaedrus' demonstrator. Journal of Management Education, 31(6), 797-811.

Moreno-Guerrero, A. J., Rodríguez-Jiménez, C., Gómez-García, G., \& Ramos Navas-Parejo, M. (2020). Educational innovation in higher education: Use of role playing and educational video in future teachers' training. Sustainability, 12(6), 2558. https://doi.org/10.3390/su12062558

Mtsi, N., \& Maphosa, C. (2016). Challenges encountered in the teaching and learning of the natural sciences in rural schools in South Africa. Journal of Social Sciences, 47(1), 58-67.

Nwike, M. C., \& Catherine, O. (2013). Effects of use of instructional materials onstudents cognitive achievement in agricultural science. Journal of Educational and Social Research, 3(5), 103.

Okobia, E. O. (2011). Availability and teachers' use of instructional materials and resources in the implementation of social studies in junior secondary schools in Edo State, Nigeria. Review of European Studies, 3(2), 90.

Olawale, S. K. (2013). The use of instructional materials for effective learning of Islamic studies. Jihat Al-Islam, 6(2), 29-40.

Olayinka, A. R. B. (2016). Effects of instructional materials on secondary schools students' academic achievement in social studies in Ekiti State, Nigeria. World Journal of Education, 6(1), 32-39.

Opare, S. A., Manu, F. O., Ackah, J. K., \& Akrosumah, S. M. (2018). An investigation into teaching and learning materials (TLMs) science tutors use to assess physics lessons in the colleges of education in Ghana. American Journal of Modern Physics and Application, 5(4), 91-96.

Rodrigues, I. B., Adachi, J. D., Beattie, K. A., Lau, A., \& MacDermid, J. C. (2019). Determining known-group validity and test-retest reliability in the PEQ (personalized exercise questionnaire). BMC Musculoskeletal Disorders, 20(1), 373.

Shri, K. M. (2013). Use of teaching learning materials in science at upper primary school in Mandleshwar Khargone, (Madhya Pradesh): An analysis. International Journal of Scientific and Engstepheineering Research, 4(2), 22295518.

Towsep, P., \& Anamuah-Mensah, J. (1991). Science and technology in Ghana. Science Education International, 2(2), 31-34.

Yeboah, R., Abonyi, U. K., Luguterah, A. W., \& Chapman, D. L. (2019). Making primary school science education more practical through appropriate interactive instructional resources: A case study of Ghana. Cogent Education, 6(1), 1611033. 